\title{
AN EXPERIMENTAL INVESTIGATION ON SUSTAINED DRUG DELIVERY OF RIBOFLAVIN
}

\author{
Sagar J S 1 , G M Madhu' ${ }^{1}$ V Venkatesham², J. Koteswararao ${ }^{3}$, G K MahadevaRaju ${ }^{4}$ \\ ${ }^{1}$ Department of Chemical Engineering, M S Ramaiah Institute of Technology, Bangalore - 560054, India \\ ${ }^{2}$ Department of Chemical Engineering, M S Ramaiah Institute of Technology, Bangalore - 560054, India \\ ${ }^{3}$ Department of Chemical Engineering, M S Ramaiah Institute of Technology, Bangalore - 560054, India \\ ${ }^{4}$ Department of Chemical Engineering, Dayananda Sagar College of Engineering, Bangalore - 560079, India
}

\begin{abstract}
The purpose of controlling drug delivery is to achieve more effective therapies while eliminating the potential for both under and over dosing and maintenance of concentration of drug in plasma within therapeutic index is very critical. The conventional Oral drug delivery has limitations and produce wide range of fluctuations of drug concentration in the bloodstream and tissues with consequent undesirable toxicity and poor efficiency and also repetitive dosing and unpredictable absorption. And hence the concept of oral Sustained release drug delivery systems has become prominent, which works on many different mechanisms.
\end{abstract}

This work deals with the development of a sustained drug delivery system using riboflavin as the model drug in an IN-VITRO condition. A drug delivery system is fabricated using Poly Vinyl Alcohol (PVA). The effect of temperature and pH are considered to understand the effectiveness of the system. The results of experimental studies are compared with predictions from mass transfer model and Ritger-Peppas model and are in good agreement

\section{INTRODUCTION}

A drug is basically, a chemical substance that has known to have biological effects on humans or other animals and is used in the diagnosis, prevention, treatment, cure of disease or used to enhance physical or mental well-being. Recreational drugs are chemical substances that affect the central nervous system, such as opioids or hallucinogens [1]. Alcohol, nicotine, and caffeine are the most widely used psychotropic drugs worldwide [2].

Drugs should be used for a limited duration or on a regular basis for chronic disorders and administered into a patient's body to have desired therapeutic effect in the system, like curing a disease. Drug delivery implies the transport of a drug from one part to another part of the body and technology used for achieve the effect safely [3]. Drug delivery can also be a combined effect of dosage form and the way in which it is administered [4]. The process involves drug reaching the target site and facilitate the reaction. Both these steps depend on the body mass and time in which the presence of drug in the body. Sometimes it includes medical devices and also the combination of drug and devices.

Drug delivery technologies modify drug release profile, absorption, distribution and elimination for the benefit of improving product efficacy and safety as well as patient convenience and compliance. Drug release is due to diffusion, degradation, swelling, and affinity-based mechanisms. Most common routes of administration include the preferred non-invasive per oral, topical, trans-mucosal, and inhalation routes. Many medications such as peptide and protein, antibody, vaccine and gene based drugs are delivered by injection or a nano-needle as they might be susceptible to enzymatic degradation or other reasons $[5,6]$.

Sustained/ controlled release drug delivery systems have gained great advancement in the world of medicine in the recent years. The release rate of drug from the site of absorption into systemic circulation is controlled by the use of polymers in controlled delivery systems and used in oral preparations such as tablets and capsules. The particulate form of these polymers combines with the particles of the drug and thus controls the release rate of the drug from its matrix tablets in a constant manner and for specific time period either preferably up to 24 hours. The drug plasma level is maintained to an optimum range so as to reduce the toxicities. The drug release rate is directly influenced by several factors in that are directly related to properties of the drug and its dosage form. Mainly, these factors are polymerassociated (amount of polymer, molecular weight, particle size and concentration)and show a tremendous influence in drug release. The concentration of polymer is most influencing among these factors. The drug to polymer ratio increases the drug release rate from the cellulosic matrices. Biocompatibility, flexibility in size and shape, ability to entrap bio-molecules as well as cells make alginate based systems ideal for drug delivery [7].

\section{MATERIALS AND METHODS}

Riboflavin is vitamin B2 and earlier known as vitamin $G$ [8], is an easily absorbed coloured micronutrient. Vitamin $\mathrm{B} 2$ is required for a wide variety of cellular processes [9]. 
Polyvinyl alcohol $\left(\left[\mathrm{CH}_{2} \mathrm{CH}(\mathrm{OH})\right]_{\mathrm{n}}\right)$ is a water-soluble synthetic polymer. It is used in tablet and capsule making, papermaking, textiles, and a variety of coatings. It is white (colorless) and odorless and also sometimes supplied as beads or solutions in water [10]

To find the drug delivery system performance various batch experiments are conducted, the drug is used in the form of tablets prepared with the help of poly vinyl alcohol. The detailed procedures are given below.

\subsection{Preparation of PVA Tablets}

A clear solution of PVA is prepared by dissolving measured quantity of PVA crystals in hot water at $80^{\circ} \mathrm{C}$ the temperature during which is maintained for at least $6 \mathrm{~h}$ and then cooled to room temperature. $100 \mathrm{ml}$ of this solution is taken in a beaker and desired quantity of riboflavin is added. The solution is heated at $80^{\circ} \mathrm{C}$ and placed in a sonicator for about half an hour. The solution is then cooled down and transferred into moulds as shown in Figure 1. The moulds are allowed to dry at room temperature for 3 to 4 days and dry tablets are obtained in desired shape as shown in Figure 2 and are stored for use in the batch experiments later.

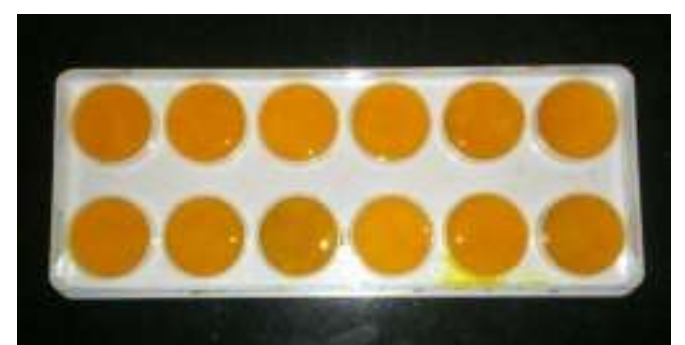

Fig 1 Moulds used for preparing PVA-Riboflavin tablets

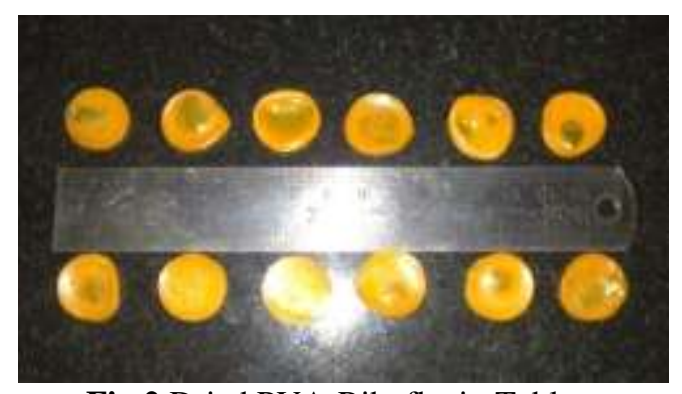

Fig 2 Dried PVA-Riboflavin Tablets

PVA-Riboflavin tablets as prepared used to study the effect of temperature and $\mathrm{pH}$ which have influence on drug release rate. The mechanism of the rate control is also investigated.

\subsection{Batch Drug Release Experiments}

The experiments were conducted in a batch reactor which consists of a cylindrical vessel of volume $150 \mathrm{ml}(100 \mathrm{ml}$ of drug solution can be used) and a magnetic stirrer. By changing the power input to the stirrer the temperature and speed of agitation can be controlled. The following procedure is adopted to find drug release rates.

$100 \mathrm{ml}$ of de-ionized water is taken in the batch reactor and PVA tablets are transferred. The reactor is placed on the stirrer tuned for required agitation speed, temperature and time is switched-on. Samples are pipetted out carefully for every $5 \mathrm{~min}$ up to $60 \mathrm{~min}$ and analyzed for riboflavin using the spectrophotometer at $446 \mathrm{~nm}$ by measuring absorbance. Later the sample is transferred to the beaker to maintain constant volume. The experiment is repeated for various temperatures and $\mathrm{pH}$ of solution. The $\mathrm{pH}$ is varied using $0.1 \mathrm{~N} \mathrm{HCl}$ and $0.1 \mathrm{~N} \mathrm{NaOH}$.

The experimental data are fitted using two models: RitgerPeppasand mass transfer (developed in this study) models.

\section{THEORITICAL ANALYSES}

\subsection{Ritger-Peppas Model}

This model is most widely used to describe drug release from a polymer and is named after the proposers $[11,12]$ and given by the equation 1 .

$$
\mathrm{F}=\frac{\mathrm{C}}{\mathrm{C}_{\infty}}=\mathrm{kt}^{\mathrm{n}}
$$

Where,

$\mathrm{C}=$ mass of the $\mathrm{drug}$ (in ppm) released at time $\mathrm{t}$

$C_{\infty} \quad=$ mass of drug $(\mathrm{ppm})$ released after infinite time

$\mathrm{F} \quad=$ fraction released

$\mathrm{k} \quad=$ mass transfer coefficient

$\mathrm{n}=$ constant $\mathrm{n}=0.85$ for sphere and $\mathrm{n}=1$ for slab

Upon differentiating Eqn. 1with time, the normalised release rated $\mathrm{F} / \mathrm{dt}$, is obtained (Equation 2).

$$
\frac{\mathrm{dF}}{\mathrm{dt}}=\mathrm{knt}^{\mathrm{n}-1}
$$

\subsection{Mathematical Model Proposed}

In general a drug delivery process consists of a drug in the form of solid or liquid enclosed in a capsule and a solution into which the drug has to be transferred across surface of the solid or the membrane of the capsule. The process is represented schematically in Figure 3. The drug enclosed in a spherical matrix made of polymeric material. The membrane is assumed to be permeable to drug. These spherical beads are immersed in a solution into which the drug has to be released. The resistance offered by the membrane determines predominantly the drug release rate. As per the theory of mass transfer this rate is function of the concentration gradient available across the membrane. But as per the physical nature of the problem the following steps take place during the transfer of drug.

1. As soon as the drug tablets are immersed in the solution, the solution diffuses into the interior of the tablet. This step is assumed to be very fast and do not affect the rate of drug delivery.

2. The drug dissolves in the water with which it is in contact on the surface and the concentration can be assumed as its solubility which is constant at particular temperature at the solid-liquid interface surrounding inside the membrane. 
3. Transfer of drug across the film to the surface of the membrane.

4. Transfer of the drug from interior surface to external surface of the membrane.

5. Transfer across the liquid film surrounding the external surface of the membrane.

6. Transfer of drug from the interface to the bulk of the liquid into which the drug has to be dispersed.

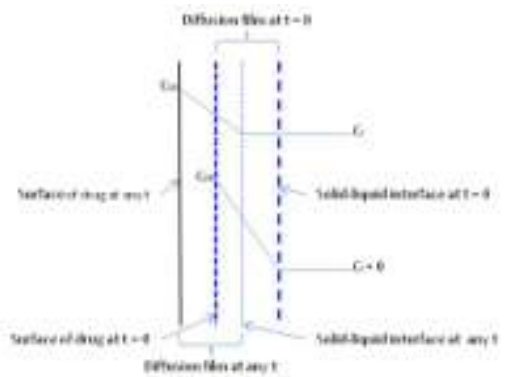

Fig 3 Drug delivery process based on proposed model

If the bulk of liquid outside is assumed to be well stirred then step 5 will have no effect on the overall process and the problem simplifies to two-film theory (TFT) of mass transfer [13]. As per two film theory the overall mass flux of the drug $(\mathrm{A})$ at time $\mathrm{t}$ can be written as:

$$
\text { Mass flux }=m_{A}=k_{n}\left(C_{S 0}-C_{l}\right)
$$

Where $K_{n}=$ overall mass transfer co-efficient. The total mass of A transferred if number of tablets [volume (V) and surface area $\left(A_{s}\right)$ ] present in a solution of volume $V_{0}$ is $n$,

$$
\begin{gathered}
\mathrm{n}_{\mathrm{t}} \mathrm{m}_{\mathrm{A}}=\mathrm{k}_{\mathrm{n}}\left(\mathrm{C}_{\mathrm{S} 0}-\mathrm{C}_{\mathrm{l}}\right) \times \mathrm{A}_{\mathrm{s}} \cdot \mathrm{n}_{\mathrm{t}} \\
\mathrm{n}_{\mathrm{t}} \mathrm{m}_{\mathrm{A}}=\frac{\mathrm{dC}_{\mathrm{l}} \mathrm{V}_{0}}{\mathrm{dt}} \\
\frac{\mathrm{dC} \mathrm{l}}{\mathrm{dt}}=\frac{\mathrm{k}_{\mathrm{n}} \mathrm{A}_{\mathrm{s}}\left(\mathrm{C}_{\mathrm{S} 0}-\mathrm{C}_{\mathrm{l}}\right)}{\mathrm{V}_{0}} \\
\frac{\mathrm{dC}}{\mathrm{dt}}=\mathrm{K}^{\mathrm{I}}\left(\mathrm{C}_{\mathrm{S} 0}-\mathrm{C}_{\mathrm{l}}\right)
\end{gathered}
$$

Where,

$\mathrm{C}_{\mathrm{I}} \quad=$ Concentration of drug in bulk

$\mathrm{C}_{\mathrm{SO}}=$ Concentration of drug at solid-liquid interface

$\mathrm{K}^{\mathrm{I}} \quad=$ Lumped parameter which includes mass

transfer coefficient

$\mathrm{V}_{\mathrm{o}} \quad=$ Volume of the solution containing drug

$\mathrm{t}=$ Time of transfer

$\mathrm{m}_{\mathrm{A}} \quad=$ Mass of drug contained in single tablets

$\mathrm{n}_{\mathrm{t}} \quad=$ Number of tablets in $\mathrm{V}_{\mathrm{o}}$

The integration of equation 7 between the limits shown below the solution can be obtained.

$$
\begin{aligned}
& t=\mathrm{t} ; C_{l}=\mathrm{C}_{\mathrm{l}} \text { and } \mathrm{t}=0 ; C_{l}=\mathrm{C}_{\mathrm{l} 0} \\
& \ln \left(\frac{\mathrm{C}_{\mathrm{S} 0}-\mathrm{C}_{10}}{\mathrm{C}_{\mathrm{S} 0}-\mathrm{C}_{\mathrm{l}}}\right)=\mathrm{K}^{\mathrm{I}} \mathrm{t}
\end{aligned}
$$

As per Ritger- Peppas [11] the rate of change of drug release can be expressed as:

$$
\frac{\mathrm{C}_{\mathrm{l}}}{\mathrm{C}_{\mathrm{l} \infty}}=\mathrm{K}^{\mathrm{II}} t
$$

Comparing equations 7 and 10 , it is easily understood that $\left(\mathrm{C}_{\mathrm{S} 0}-\mathrm{C}_{\mathrm{l}}\right)$ must vary as $\mathrm{t}^{2}$ and $\mathrm{K}^{\mathrm{I}}=\mathrm{K}^{\mathrm{II}} \mathrm{C}_{\mathrm{l} \infty}$, then RitgerPeppas model and proposed model in the present work predict the behaviour in similar way.

\section{RESULTS AND DISCUSSION}

Batch experiments are conducted using PVA tablets prepared and as explained before. In these experiments effect of different factors (Temperature and $\mathrm{pH}$ ) are investigated.

\subsection{Effect of $\mathrm{pH}$}

To study effect of $\mathrm{pH}$, experiments are conducted by keeping the temperature constant at $28^{\circ} \mathrm{C}$ and varying $\mathrm{pH}$ in the range 4 to 9 . The experiments also conducted at $40^{\circ} \mathrm{C}$. The data are fitted as per the proposed model are presented in Figure 4 and Figure 6. The same are also presented as per the model of Ritger-Peppas in Figure 5 and Figure 7. The comparison of results is given in Table 1.

From the plots of Figures 4 and 5 it can be observed that both models predict an increase in the slope with increase in $\mathrm{pH}$ at $28^{\circ} \mathrm{C}$ and at higher $\mathrm{pH}$ the increase is marginal. But for sustained drug release the slope i.e., mass transfer coefficients must be lower hence the lower $\mathrm{pH}$ is suitable for the design. It can also be noted from Figure 5 that the release rate flattens after about 4 hours and even after 6 hours around $35 \%$ of the drug only released into the solution from the tablets. Hence it can be inferred that several hours more are required for complete release of drug. If the drug is consumed simultaneously then complete removal can be observed as in the case of an affected human system. Hence equilibrium was reached in the experiments (i.e., observed flatness in the plots for lower $\mathrm{pH}$ ).

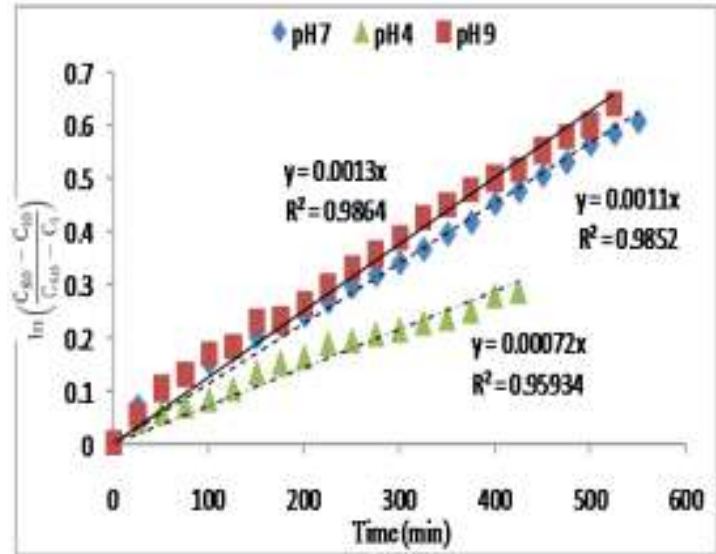

Fig 4 Effect of $\mathrm{pH}$ on Riboflavin release for PVA tablets as per model proposed in this study $\left(28^{0} \mathrm{C}\right)$ 


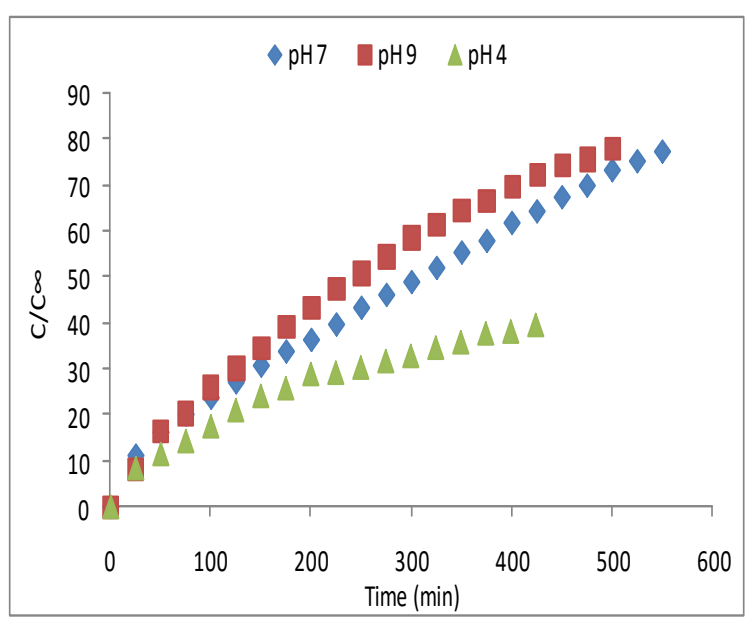

Fig 5 Effect of pH on Riboflavin release for PVA tablets as per Ritger-Peppas model $\left(28^{\circ} \mathrm{C}\right)$

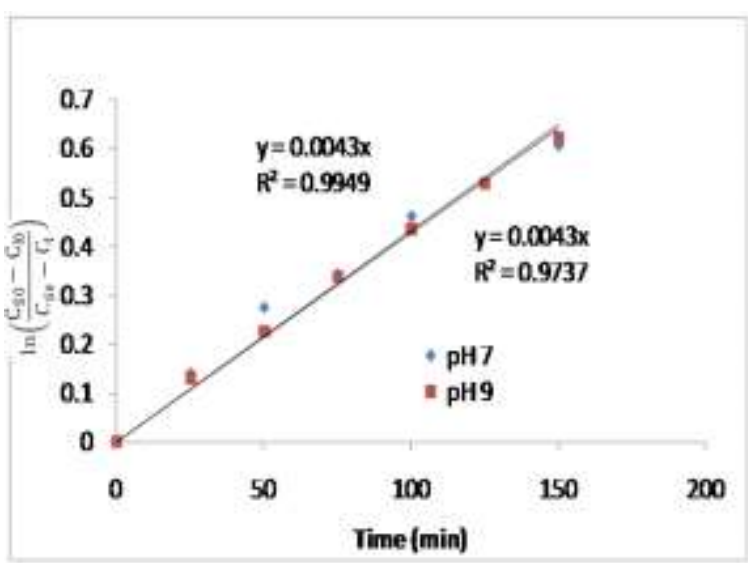

Fig 6 Effect of $\mathrm{pH}$ on Riboflavin release for PVA tablets as per model proposed in this study $\left(40^{\circ} \mathrm{C}\right)$

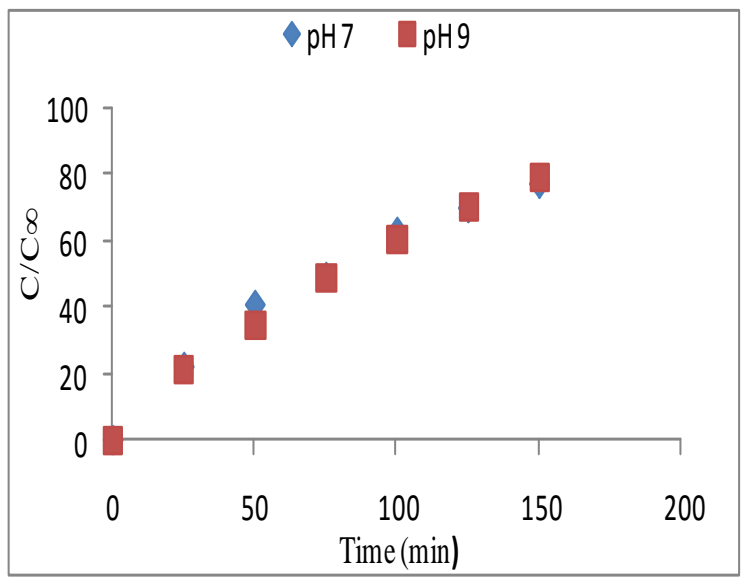

Fig 7 Effect of pH on Riboflavin release for PVA tablets as per Ritger-Peppas model $\left(40^{\circ} \mathrm{C}\right)$

From the Figure 6 and Figure 7 (at $40^{\circ} \mathrm{C}$ ), the effect of $\mathrm{pH}$ is found as minimal and similar rates of drug release were observed and the slopes are almost four times higher indicating high mass transfer rates and which is not the requirement for good sustained drug delivery systems. Hence lower temperatures and $\mathrm{pH}$ values can be said to be best for these systems.
Table 1 Slopes of drug release plots obtained for both the models tested

\begin{tabular}{|c|c|c|c|c|c|c|}
\hline \multirow{3}{*}{$\begin{array}{l}\text { Temperat } \\
\text { ure } \\
\left({ }^{0} \mathrm{C}\right)\end{array}$} & \multicolumn{3}{|c|}{ Proposed Model } & \multicolumn{3}{|c|}{$\begin{array}{l}\text { Ritger-Peppas } \\
\text { model }\end{array}$} \\
\hline & \multicolumn{6}{|l|}{ pH } \\
\hline & 4 & 7 & 9 & 4 & 7 & 9 \\
\hline 28 & $\begin{array}{l}0.000 \\
72\end{array}$ & $\begin{array}{l}0.001 \\
1\end{array}$ & $\begin{array}{l}0.00 \\
13\end{array}$ & $\begin{array}{l}0.15 \\
41\end{array}$ & $\begin{array}{l}0.20 \\
65\end{array}$ & $\begin{array}{l}0.17 \\
05\end{array}$ \\
\hline 40 & - & $\begin{array}{l}0.004 \\
33\end{array}$ & $\begin{array}{l}0.00 \\
43\end{array}$ & - & $\begin{array}{l}0.57 \\
85\end{array}$ & $\begin{array}{l}0.46 \\
65\end{array}$ \\
\hline
\end{tabular}

\subsection{Effect of Temperature}

The experiments to find the effect of temperature on the drug release rate are conducted keeping the $\mathrm{pH}$ constant and varying the temperature in the range of 28 to $40^{\circ} \mathrm{C}$. The results of these experiments conducted at $\mathrm{pH} 8$ and $\mathrm{pH}$ 10are fitted as per both models. Figure 8 and Figure 10 represent proposed model. Figure 9 and Figure 10 represent RitgerPeppas model. The comparison of the results between these models is given in Table 2 .

From the plots of Figure 8 and Figure 10 it can be said that both models predict an increase in the slope with increase in temperature at $\mathrm{pH} 9$ and at lower the temperature lower is the rate of drug release. The similar trend was observed for the experiments conducted at lower $\mathrm{pH}$ of 7 and seen from Figure 9 and Figure 11. The rates were found to be lower at lower temperature and lower $\mathrm{pH}$ values. But at higher $\mathrm{pH}$ the slope of the line for both temperatures is same indicating the temperature does not affect the process much. But for sustained drug release the slope i.e., mass transfer coefficients must be lower and hence the lower temperatures are suitable for the design.

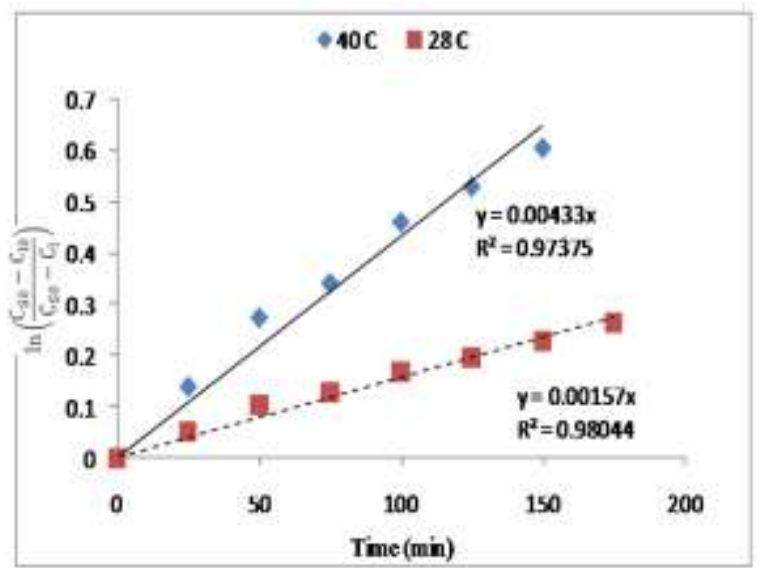

Fig 8 Effect of temperature on Riboflavin release for PVA tablets as per model proposed in this study ( $\mathrm{pH} 9)$ 


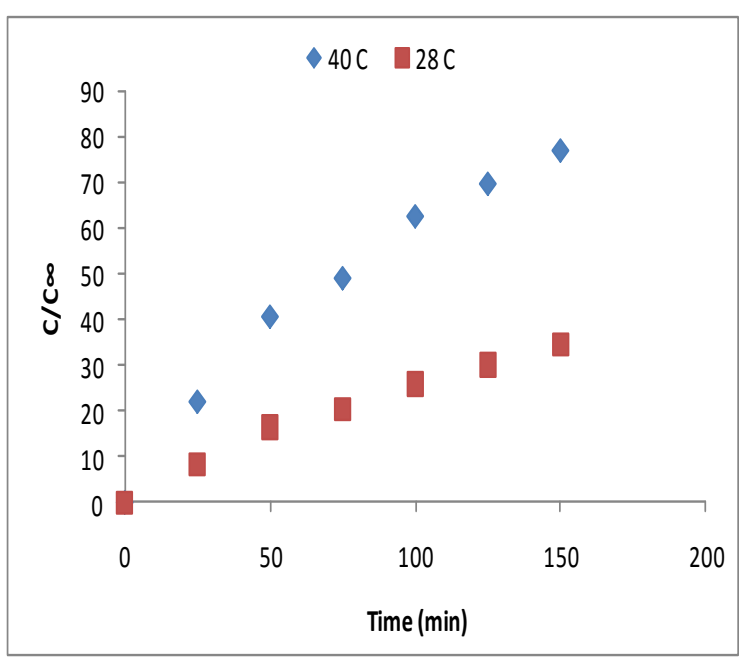

Fig 9: Effect of temperature on Riboflavin release for PVA tablets as per Ritger and Peppas model ( $\mathrm{pH}$ 9)

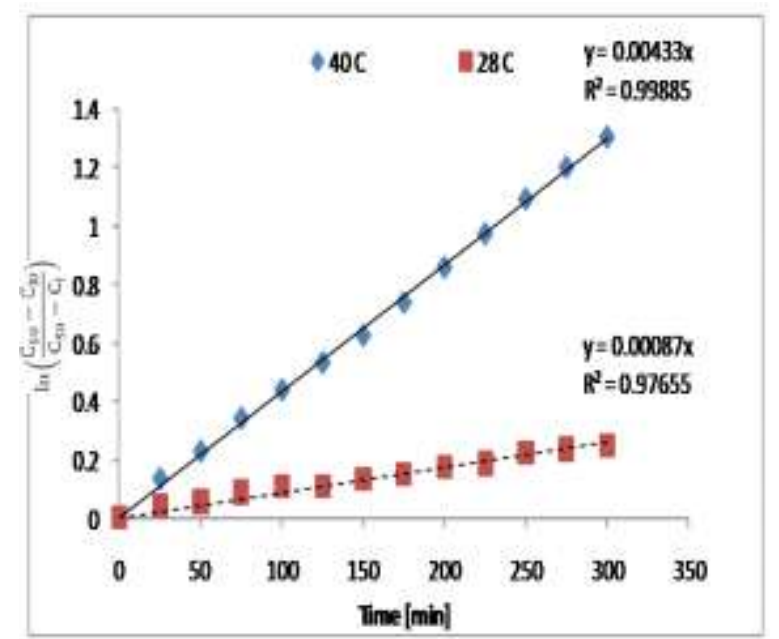

Fig 10 Effect of temperature on Riboflavin release for PVA tablets as per model proposed in this study $(\mathrm{pH} 7)$

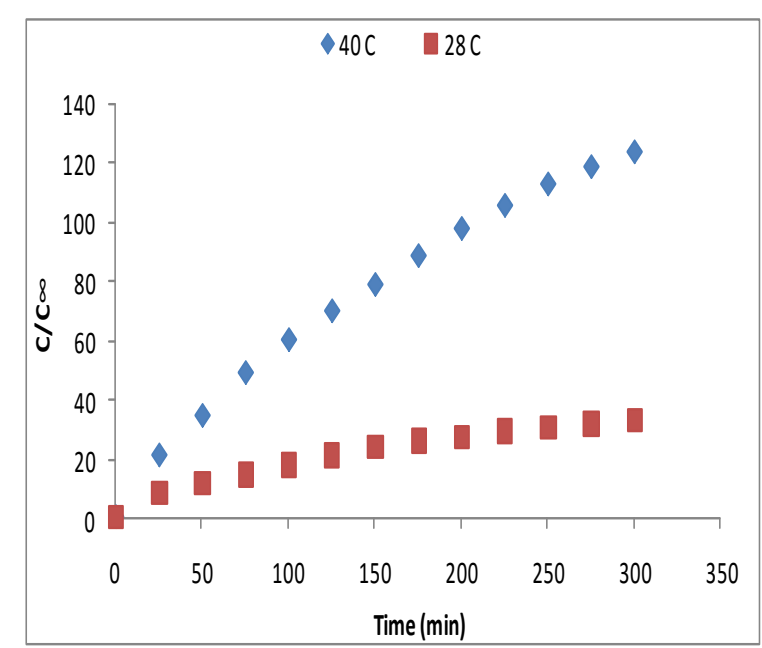

Fig 11 Effect of temperature on Riboflavin release for PVA tablets as per Ritger-Peppas model ( $\mathrm{pH} 7$ )
Table 2 Estimated mass transfer coefficients as per the models tested

\begin{tabular}{|c|c|c|c|c|c|c|}
\hline \multirow{3}{*}{$\begin{array}{l}\text { Temperat } \\
\text { ure } \\
\left({ }^{0} \mathrm{C}\right)\end{array}$} & \multicolumn{3}{|c|}{ Proposed Model } & \multicolumn{3}{|c|}{$\begin{array}{l}\text { Ritger-Peppas } \\
\text { model }\end{array}$} \\
\hline & \multicolumn{6}{|l|}{$\mathbf{p H}$} \\
\hline & 4 & 7 & 9 & 4 & 7 & 9 \\
\hline 28 & $\begin{array}{l}0.000 \\
72\end{array}$ & $\begin{array}{l}0.001 \\
1\end{array}$ & $\begin{array}{l}0.00 \\
13\end{array}$ & $\begin{array}{l}0.000 \\
45\end{array}$ & $\begin{array}{l}0.00 \\
06\end{array}$ & $\begin{array}{l}0.00 \\
05\end{array}$ \\
\hline 40 & - & $\begin{array}{l}0.004 \\
33\end{array}$ & $\begin{array}{l}0.00 \\
43\end{array}$ & - & $\begin{array}{l}0.00 \\
17\end{array}$ & $\begin{array}{l}0.00 \\
13\end{array}$ \\
\hline
\end{tabular}

\section{CONCLUSION}

In the present work the model drug used is riboflavin, which is vitamin $\mathrm{B}_{2}$, and PVA polymer for preparing tablets. The experiments are conducted to find the effects of $\mathrm{pH}$ (at $\mathrm{pH} 4$, 7 and 9) and temperature $\left(28\right.$ and $\left.40^{\circ} \mathrm{C}\right)$ on drug release rate from PVA tablets. The results of these experiments are fitted as per the proposed model and Ritger-Peppas model. The results predicted lower temperatures and $\mathrm{pH}$ are most suitable for effective release of Riboflavin drug from PVA tablets. These results and models can be easily extended to any other suitable drug and also tablets made using different polymeric materials. At lower conditions $\left(4 \mathrm{pH}\right.$ and $\left.28^{\circ} \mathrm{C}\right)$ the mass transfer coefficient is predicted as $7.2 \times 10^{-4} \mathrm{~ms}^{-1}$ by proposed model and $4.5 \times 10^{-4} \mathrm{~ms}^{-1}$ by Ritger-Peppas model.

\section{REFERENCES}

[1] "Drug." The American Heritage Science Dictionary, Houghton Mifflin Company, via dictionary.com, 20 September 2007.

[2] http://www.ncbi.nlm.nih.gov/pmc/articles/PMC31816 22/

[3] Langer, R., EtihMathiowitz, John Wiley and sons, "Encyclopaedia of Controlled Drug Delivery system", Journal of Pharma Sciences, 2, 1999, pp 415-436.

[4] Stephanie Farrell and Jennifer Vernenho, “ A Controlled Drug Delivery Experiment using Alginate Beads", Journal of Chemical Engineers Laboratory, 46, 2012, pp97 - 109.

[5] Ghosh, L. K., Ghosh, N. C., Chatterjee, M. Gupta, B. K., "Product Development Studies on the Tablet Formulation of Ibuprofen to Improve Bioavailability", Journal Drug Dev. Ind. Pharm., 24 (5), 1998, pp473-477.

[6] Centre for Drug Evaluation and Research, "US Department of Health and Human Services, Food and Drug Administration", Journal Guidance for Industry: Dissolution Testing of Immediate Release Solid Dosage Forms, 1997, pp4 -10.

[7] Falk, R, Randoplh, T. W: Meyer, J, D,: Kelly, R, M, Manning, "Controlled Release of drugs", Journal of Nanomedicine, 7, 1996, pp5451 - 5463.

[8] David Bennett (27 July 2013). "Every Vitamin Page: All Vitamins and Pseudo-Vitamins". lifeinyouryears.net. Retrieved 17 May 2014. 
[9] Higdon, Jane; Victoria J. Drake (2007). "Riboflavin" Micronutrient Information Center. Linus Pauling Institute at Oregon State University. Retrieved December 3, 2009

[10] Manfred L. Hallensleben "Polyvinyl Compounds, Others" in Ullmann's Encyclopedia of Industrial Chemistry, 2000, Wiley-VCH, Weinheim.doi:10.1002/14356007.a21_743

[11] Ritger, Philip L. and Nikolaos A. Peppas, "Fickian and anomalous release from swellable devices", Journal of Controlled Release, 5(1), 1987, pp37-42.

[12] Peppas, Nikolaos A. and Jennifer J. Sahlin, "Coupling of diffusion and relaxation", International Journal of Pharmaceutics, 57(1), 1989, pp169-172.

[13] Robert E.Treybal; Mass Transfer Operations, Third edition; pp107-110. 